\title{
The surface $\mathrm{CO}_{2}$ gradient and pore-space storage flux in a high-porosity litter layer
}

\author{
By ADAM I. HIRSCH ${ }^{1 *} \dagger$, SUSAN E. TRUMBORE and MICHAEL L. GOULDEN, ${ }^{1}$ Department \\ of Earth System Science, University of California, Irvine, CA 92697-3100, USA; ${ }^{2}$ Department of Earth System \\ Science, University of California, Irvine, CA 92697-3100, USA; ${ }^{3}$ Department of Earth System Science, University of \\ California, Irvine, CA 92697-3100, USA
}

(Manuscript received 25 June 2003; in final form 16 March 2004)

\begin{abstract}
We present an hourly time series of the $\mathrm{CO}_{2}$ concentration profile in the top $20 \mathrm{~cm}$ of a boreal forest litter layer at a site in northern Manitoba, Canada. The profile data, measured with an automated sampling system during the summer of 1999 , show a pronounced daily cycle, with a small surface $\mathrm{CO}_{2}$ gradient and low concentrations during the day and a large surface gradient and high concentrations at night. The $\mathrm{CO}_{2}$ profile measurements allow us to test two current assumptions built into measurements of ecosystem carbon fluxes. The first assumption is that the flux from the surface to the atmosphere can be calculated using the measured $\mathrm{CO}_{2}$ gradient and a calculated value of the diffusive transport coefficient. The behaviour of the surface $\mathrm{CO}_{2}$ gradient suggests that one cannot assume diffusive transport across the moss surface at this site when the friction velocity measured at $30 \mathrm{~m}$ exceeds $0.4 \mathrm{~m} \mathrm{~s}^{-1}$. This condition, associated with turbulent mixing generated by wind shear and/or solar heating of the surface, was often encountered during the day at this site, though rarely at night. During the day, friction velocity and wind speed measured at $30 \mathrm{~m}$ height are linearly related, with friction velocity exceeding $0.4 \mathrm{~m} \mathrm{~s}^{-1}$ when wind speed exceeds about $2 \mathrm{~m} \mathrm{~s}^{-1}$. At night, wind at the top of the canopy may be laminar, so that the wind speed must exceed $4 \mathrm{~m} \mathrm{~s}^{-1}$ to cause enough turbulence to raise friction velocity above the $0.4 \mathrm{~m} \mathrm{~s}^{-1}$ threshold. The second assumption is that changes in soil pore-space $\mathrm{CO}_{2}$ storage can be neglected when correcting eddy covariance measurements for ecosystem respiration that is stored in the ecosystem rather than being mixed into the overlying atmosphere. Our results show that the soil pore-space $\mathrm{CO}_{2}$ profile is not in steady state at the site, but that the magnitude of the corresponding storage flux is small relative to the below-canopy $\mathrm{CO}_{2}$ storage flux. The soil pore-space $\mathrm{CO}_{2}$ storage flux ranges between $\pm 0.4 \mu \mathrm{mol} \mathrm{m}^{-2} \mathrm{~s}^{-1}$, while the below-canopy storage flux ranges between $\pm 20 \mu \mathrm{mol} \mathrm{m}^{-2} \mathrm{~s}^{-1}$. However, the soil pore-space storage flux could be significant relative to the $\mathrm{CO}_{2}$ respiration flux across the soil surface, which we estimate to be in the range of $1-4 \mu \mathrm{mol} \mathrm{m}-2 \mathrm{~s}^{-1}$.
\end{abstract}

\section{Introduction}

This paper addresses two methodological questions in carbon cycle research. The first is whether the $\mathrm{CO}_{2}$ flux across the ground surface can always be calculated using a measured $\mathrm{CO}_{2}$ gradient and a diffusive transport coefficient, as an alternative to chamber flux techniques. Studies that utilize the $\mathrm{CO}_{2}$ profile to calculate below-ground respiration and the $\mathrm{CO}_{2}$ surface flux generally assume diffusive transport and use an equation describing Fick's first law to calculate the $\mathrm{CO}_{2}$ flux (Davidson and Trumbore, 1995; Gaudinski et al., 2000; Risk et al., 2002a):

* Now at: Cooperative Institute for Research in Environmental Science, University of Colorado at Boulder, and Climate Monitoring and Diagnostics Laboratory, National Oceanic and Atmospheric Administration, 325 Broadway, Boulder, CO 80303-3328, USA.

$\dagger$ Corresponding author.

e-mail: adam.hirsch@noaa.gov
$\mathrm{CO}_{2}$ flux $=-D_{\text {eff }}(\delta c / \delta z)$.

This method uses the measured $\mathrm{CO}_{2}$ gradient $(\delta c / \delta z$, in $\mu$ mol $\mathrm{cm}^{-4}$ or $\left.\mu \mathrm{mol} \mathrm{m}^{-4}\right)$ and a diffusive transport coefficient $\left(D_{\text {eff }}\right.$, in $\mathrm{cm}^{2} \mathrm{~s}^{-1}$ or $\mathrm{m}^{2} \mathrm{~s}^{-1}$ ) calculated from the physical properties of the soil and soil climate or transport tracer measurements to calculate the $\mathrm{CO}_{2}$ flux $\left(\mu \mathrm{mol} \mathrm{cm} \mathrm{cm}^{-2} \mathrm{~s}^{-1}\right.$ or $\left.\mu \mathrm{mol} \mathrm{m} \mathrm{m}^{-2} \mathrm{~s}^{-1}\right)$. In fine-grained mineral soils this assumption of diffusive transport is probably generally valid, except during large changes in atmospheric pressure accompanying passage of a frontal system that cause convection in the soil (Renault et al., 1998; Schery et al., 1984; Clements and Wilkening, 1974). A recent study in Canada that combined below-ground $\mathrm{CO}_{2}$ profiles and surface flux measurements suggested that in mineral soils, non-diffusive transport can become important when soils are very dry (Risk et al., 2002b). Wind has been shown to play a role in gas transport at the surface of highly porous materials such as sand (Kimball 
and Lemon, 1971). Therefore, the influence of wind on $\mathrm{CO}_{2}$ transport at the ground surface needs to be assessed before using the profile method to predict the surface $\mathrm{CO}_{2}$ flux, especially when working in ecosystems with very porous litter layers.

The second issue is whether changes in the storage of $\mathrm{CO}_{2}$ in below-ground air are significant relative to changes in the storage of $\mathrm{CO}_{2}$ from the ground surface to the top of the forest canopy, and therefore must be included in ecosystem-atmosphere carbon flux studies. In terrestrial ecosystem carbon flux measurements there is a distinction between biotic fluxes and measured fluxes. The biotic flux is the biologically mediated rate of $\mathrm{CO}_{2}$ production or consumption, and is the quantity of interest in carbon cycle studies. Below-ground biotic fluxes include respiration by microbes and soil fauna, respiration by plant roots, and both respiration and photosynthesis by low-stature plants like bryophytes. Ecosystem biotic fluxes include the below-ground biotic fluxes as well as above-ground plant respiration and photosynthesis. Measured fluxes include, among others, chamber flux measurements of ground surface fluxes and eddy covariance measurements of the net ecosystem $\mathrm{CO}_{2}$ exchange.

At any given point in time the measured flux and biotic flux may differ due to a change in the amount of $\mathrm{CO}_{2}$ stored in the air in the ecosystem (called the $\mathrm{CO}_{2}$ storage flux) caused by changes in gas transport. Unless the transport is understood, changes in the measured flux due to changes in transport can be interpreted as changes in biotic fluxes (Risk et al., 2002b). In eddy covariance studies, changes in gas transport are related to changes in eddy diffusivity, while subsurface transport may be altered by changes in diffusivity accompanying wetting or drying and advective mechanisms such as pressure pumping, surface drag or convection caused by infiltration of water. The importance of storage flux has been recognized for some time in eddy covariance studies where the below-canopy storage flux must be added to the eddy covariance measured flux to calculate the ecosystem biotic flux (for simplicity, we are neglecting here the influence of advection on canopy storage). However, the calculation of the below-canopy storage traditionally ends at the soil surface, neglecting $\mathrm{CO}_{2}$ storage changes in litter and soil air.
We define the below-ground pore-space $\mathrm{CO}_{2}$ storage flux as the change in $\mathrm{CO}_{2}$ storage in litter and mineral soil air-filled pore space with time, analogous to the below-canopy storage flux. Thus far, there has been no assessment of the magnitude of changes in the below-ground soil pore-space storage relative to the above-ground storage flux. Chamber flux studies also neglect changes in soil pore-space $\mathrm{CO}_{2}$ storage. Measurement of the below-ground pore-space storage flux could help correct for anomalies in chamber flux measurements related to changes in atmospheric pressure or chamber pressurization (Lund et al., 1999).

Automated measurements of the below-ground $\mathrm{CO}_{2}$ profile were made hourly during the summer of 1999 at the BOREAS (Sellers et al., 1997) Northern Old Black Spruce site allow us to test the assumptions of diffusive transport and negligible belowground $\mathrm{CO}_{2}$ storage flux. The sampling system was built to study deep soil respiration (Hirsch et al., 2003), but the surface $\mathrm{CO}_{2}$ gradient and $\mathrm{CO}_{2}$ storage in the top $20 \mathrm{~cm}$ of the litter layer both showed an unexpectedly dynamic daily cycle, suggesting that the two assumptions are not valid for high-porosity litter layers. The suite of high-temporal-resolution measurements at the site, including automated flux chambers and concurrent below-canopy $\mathrm{CO}_{2}$ profile measurements, allow us, in theory, to diagnose daily changes in $\mathrm{CO}_{2}$ transport at the moss surface and to assess the magnitude of the pore-space $\mathrm{CO}_{2}$ storage flux relative to the below-canopy storage flux. Micrometeorological measurements made on the tower used for the eddy covariance study provide auxiliary measurements to help explain the observed daily cycles in the surface gradient and below-ground pore-space $\mathrm{CO}_{2}$ storage.

\section{Methods}

\subsection{Automated sampling system}

A diagram of the automated sampling system is shown in Fig. 1. At each depth, air is withdrawn hourly from the soil air-filled pore space by a $12 \mathrm{~V}$ diaphragm pump (catalogue number UNMP30KNDC, KNF Neuberger Air and Gas Pumps, Freiburg,
Fig 1. Automated $\mathrm{CO}_{2}$ profile sampling system. Arrows represent the direction of air flow.

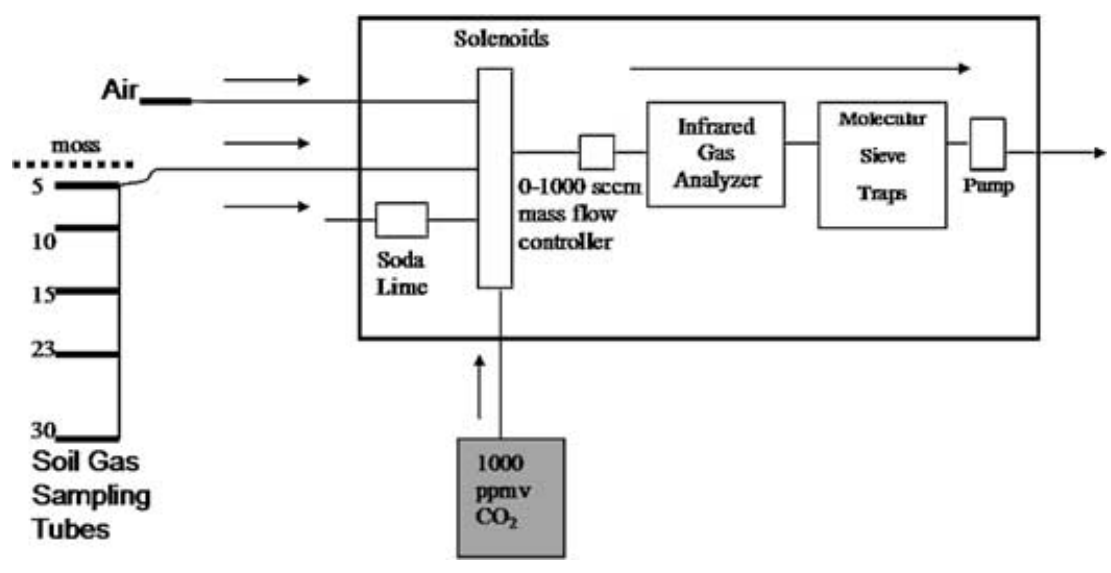


Germany) through a $25-\mathrm{cm}$ long piece of high-density microporous Teflon tubing (product code 032-03, International Polymer Engineering, Inc., Tempe, AZ; internal diameter $3.3 \pm 0.2 \mathrm{~mm}$; wall thickness $1.65 \pm 0.1 \mathrm{~mm}$; density none $<0.800 \mathrm{~g} \mathrm{~cm}^{-3}$ ). Though expensive, microporous Teflon tubing is useful in wet soils because it excludes liquid water while allowing gas exchange. The microporous Teflon tubing also allows air to be drawn from the soil over the entire length of the tube $(25 \mathrm{~cm})$ rather than from a point, decreasing disturbance of the soil $\mathrm{CO}_{2}$ profile. However, tests were not performed with the explicit purpose of determining whether air was sampled uniformly along the length of the tube. The implications of non-uniform sampling are explored in Section 3.4. The soil air is drawn through $1 / 8$ in outer diameter polyethylene tubing into a solenoid manifold, which selects between different depths using two-way electronic pneumatic solenoid valves (catalogue number EV-2M-12B, Clippard Co., Cincinnati, OH). The pump and solenoids are controlled by a data logger/control module (catalogue number CR10X-1M, Campbell Scientific, Logan, UT), via relay units (catalogue number SDM-CD16AC, Campbell Scientific). After entering the sampling system, the air is heated with a $50 \mathrm{~W}$ heating pad, dried with a Nafion drier (catalogue number MD-05024F, Permapure Inc., Toms River, NJ) and filtered with a Gelman $50 \mathrm{~mm}$ Teflon membrane filter (catalogue number 9967-008, Licor Inc., Lincoln, NB). Flow is controlled by a $0-1000 \mathrm{sccm}$ mass-flow controller (catalogue number 1179A13CS1BV, MKS Instruments, Andover, MA), with the set point controlled by the data logger.

Each depth is sampled for $2 \mathrm{~min}$ at a flow rate of $120 \mathrm{sccm}$, the first minute to flush the previous sample and the second minute for recording the concentration. During the second minute, the average and standard deviation of the $\mathrm{CO}_{2} \mathrm{mV}$ signal and detector cell temperature of the infrared gas analyser (catalogue number LI-6252, Li-cor Inc.) are calculated and recorded by the data logger. The maximum concentration during the first minute of sampling is also recorded, for comparison with the average during the second minute of sampling. The difference gives a measure of the impact of our sampling strategy on the below-ground $\mathrm{CO}_{2}$ profile. The pressure in the detection cell is also monitored using an absolute pressure sensor (MKS Instruments 0-1000 Torr Baratron pressure transducer, catalogue number 122BA-01000AB) and the 1-min average recorded by the data logger. The system can be operated at pressures significantly below ambient, $85 \mathrm{kPa}$ in this study, which allows measurement of soil $\mathrm{CO}_{2}$ concentrations that exceed the usual limit of the IRGA (3000 parts per million by volume (ppmv)) at $1 \mathrm{~atm}$. The IRGA is zeroed once an hour using the same protocol as the profile sampling, but drawing air through a cylinder filled with soda lime rather than from the soil. The IRGA is also calibrated once an hour, again using the same sampling method, but by drawing air into the automated system from a calibration tank of 1000 ppmv $\mathrm{CO}_{2}$ in air (Scott Specialty Gas, Plumsteadville, PA). Molecular sieve traps can also be installed in the system to trap soil $\mathrm{CO}_{2}$ for later isotopic analysis (Hirsch, 2001; Hirsch et al., 2003). U-tubes containing molecular sieve $13 \mathrm{X}$ were used, each isolated from the system on both sides by two-way solenoid valves that were only opened when the profile depth corresponding to the trap was being sampled. Soil temperatures were measured at the same depths as the gas sampling tubes, with an additional measurement taken at $0.5 \mathrm{~m}$ depth. The measurements were made with type-T thermocouples, which were multiplexed (using a Campbell Scientific multiplexer, catalogue number AM25T) and recorded by the data logger.

\subsection{Site description}

Measurements were made at the BOREAS Northern Study Area Old Black Spruce site in northern Manitoba, Canada (NSAOBS or NOBS, $\left.55.88^{\circ} \mathrm{N}, 98.48^{\circ} \mathrm{W}\right)$. The ground is covered by feather moss species (Pleurozium schreberi, Hylocomium splendens) in well-drained areas and Sphagnum species (S. fuscum and $S$. warnstorfii) in lower lying, more poorly drained areas. Well-drained areas are populated by dense, 10-15 m tall black spruce (Picea mariana (Mill.) BSP), while poorly drained areas are more open, with sparse 1-6 m tall black spruce and Tamarack (Larix lariciana). The soils follow the typical boreal "L-F-H" pattern, with 30-40 cm of relatively undecomposed, highly porous moss litter ( $\mathrm{L}$ and $\mathrm{F}$ layers) overlying a dense, humic (H layer) organic carbon that can be $20-30 \mathrm{~cm}$ thick in poorly drained areas but often less than $10 \mathrm{~cm}$ thick in well-drained areas. The humic layer represents highly decomposed moss and remains of trees killed in the past by forest fires (Trumbore and Harden, 1997). The automated soil $\mathrm{CO}_{2}$ profile sampling system, described above, was installed at the NOBS site in mid-June 1999. Regular data collection began on 1 July 1999. Gas sampling tubes and thermocouples for temperature measurement were installed at 0, 5, 10, 15, 23 and $30 \mathrm{~cm}$ under Sphagnum moss. Meteorological measurements, measurements of the above-ground $\mathrm{CO}_{2}$ profile, and eddy covariance measurements (Goulden et al., 1997), begun in 1993, are still made at the site. For details of the BOREAS project see Sellers et al. (1997). Automated net ecosystem exchange (NEE) chambers are periodically deployed at the site to measure net ecosystem carbon exchange at the moss surface (Goulden and Crill, 1997; Goulden et al., 1998). To illustrate the patterns in $\mathrm{CO}_{2}$ concentrations and environmental parameters, we show a subset of our results from 1014 August 1999. This period was chosen because there was little rain $(<1 \mathrm{~mm})$, minimizing the possibility of rapid changes in the volumetric water content of the moss litter, which we assume to be constant in our calculation of the pore-space storage flux.

\subsection{Calculating storage fluxes}

Using measurements from the BOREAS Project (group TGB12; see Newcomer et al., 2000), we assume that the Sphagnum bulk density increases from $0.015 \mathrm{~g} \mathrm{~cm}^{-3}$ at the soil surface (live moss) to $0.06 \mathrm{~g} \mathrm{~cm}^{-3}$ at $30 \mathrm{~cm}$, and that soil volumetric water 
content increases from $0.15 \mathrm{~cm}^{3} \mathrm{~cm}^{-3}$ at the surface to $0.40 \mathrm{~cm}^{3}$ $\mathrm{cm}^{-3}$ at $30 \mathrm{~cm}$ depth. Soil water content was not monitored but assumed to be constant over our 5-day subset because of the short duration and lack of rain during that time. We neglect possible moisture changes related to condensation and evaporation. Air-filled pore space in the soil $\left(\mathrm{cm}^{3}\right.$ air per $\mathrm{cm}^{3}$ of soil $)$ is calculated as $1-(\mathrm{BD} / \mathrm{PD})-\mathrm{VWC}$ where BD is the soil bulk density ( $\mathrm{g}$ $\mathrm{cm}^{-3}$ ), $\mathrm{PD}$ is the density of soil organic matter (assumed here to be $1.2 \mathrm{~g} \mathrm{~cm}^{-3}$ ) and VWC is the volumetric water content of the soil $\left(\mathrm{cm}^{3}\right.$ water per $\mathrm{cm}^{3}$ of soil). The storage flux of $\mathrm{CO}_{2}$ within the top $20 \mathrm{~cm}$ of the moss litter layer is calculated using:

$\mathrm{SF}=\frac{\partial}{\partial t}\left(\int_{-0.2}^{0} a C N \partial z\right)$

First, we multiply the soil $\mathrm{CO}_{2}$ mixing ratio measured by the automated sampling system $(C, \mathrm{ppmv})$ by the air-filled porosity $\left(a, \mathrm{~m}^{3}\right.$ air per $\mathrm{m}^{3}$ soil $)$ and air number density $\left(N, \mu \mathrm{mol} \mathrm{m}^{-3}\right)$ at each depth, taking into account the soil air temperature. Then, we integrate the resulting storage from 0 to $20 \mathrm{~cm}$ below the moss surface. The change in this integrated moss litter $\mathrm{CO}_{2}$ storage with time is the below-ground pore-space $\mathrm{CO}_{2}$ storage flux (SF, $\mu \mathrm{mol} \mathrm{m} \mathrm{m}^{-2} \mathrm{~s}^{-1}$ ).

The $\mathrm{CO}_{2}$ concentration is monitored every $12 \mathrm{~min}$ at six levels $(0.3,1.5,4.6,8.4,12.9$ and $28.8 \mathrm{~m})$ in the canopy (Goulden et al., 1997). We used linear interpolation to calculate the canopy $\mathrm{CO}_{2}$ profile for 1-cm increments down to the forest floor, and integrated the profile to calculate the below-canopy $\mathrm{CO}_{2}$ storage. This storage was then converted from ppmv to $\mu \mathrm{mol} \mathrm{m}{ }^{-2}$ using barometric pressure data and temperature measured at $8 \mathrm{~m}$ on the micrometeorological tower. The change in storage with time is the storage flux, in $\mu \mathrm{mol} \mathrm{m} \mathrm{m}^{-2} \mathrm{~s}^{-1}$.

\subsection{Predicting total soil respiration}

Automated chamber flux measurements were not available during our measurement period, so we used results from a model developed from measured surface $\mathrm{CO}_{2}$ fluxes at the same site (Goulden and Crill, 1997), only 1-2 m from our profiles, to predict soil respiration as a function of our measurements of temperature at $5 \mathrm{~cm}$ below the moss surface. Chamber flux and temperature measurements at the end of the 1995 growing season yielded the following relationship between nighttime efflux $\left(\mu \mathrm{mol} \mathrm{m}{ }^{-2} \mathrm{~s}^{-1}\right)$ and $5 \mathrm{~cm}$ temperature (" $\left.T_{5 \mathrm{~cm}},{ }^{\circ} \mathrm{C}\right)$ :

flux $=\exp \left(-0.324+0.073 T_{5 \mathrm{~cm}}\right)$.

The flux chambers were designed to minimize the problems associated with flux measurement in porous moss, and included daily calibration by high- $\mathrm{CO}_{2}$ standard addition (Goulden and Crill, 1997). The exponential relationship gives a $Q_{10}$ value of about 2, consistent with the sensitivity of both moss respiration and litter decomposition with temperature. There was no error estimate given for the measurements or eq. (3), aside from a caveat that non-linearity of the infrared gas analyser and the influence of water vapour could introduce errors of $<5 \%$. We use eq. (3) to predict the total respiration that would be measured by an opaque chamber over the course of the day, and use the $\mathrm{CO}_{2}$ flux in combination with our measured surface $\mathrm{CO}_{2}$ gradient to calculate effective diffusivity, by solving for $D_{\text {eff }}$ in eq. (1). We call this calculated effective diffusivity the "apparent effective diffusivity".

\section{Results and discussion}

\subsection{The surface $\mathrm{CO}_{2}$ gradient}

The surface $\mathrm{CO}_{2}$ gradient under Sphagnum moss shows a large daily variation, with low gradients during the day and high values at night (Fig. 2). This behaviour is the opposite of what would be expected if soil respiration were controlling the $\mathrm{CO}_{2}$ gradient. According to Fick's law (eq. 1), the $\mathrm{CO}_{2}$ gradient is
Fig 2. $\mathrm{CO}_{2}$ gradient between the atmosphere and $5 \mathrm{~cm}$ below the moss surface (full circles) and friction velocity measured at 30 m (open circles), from 10-14 August 1999.

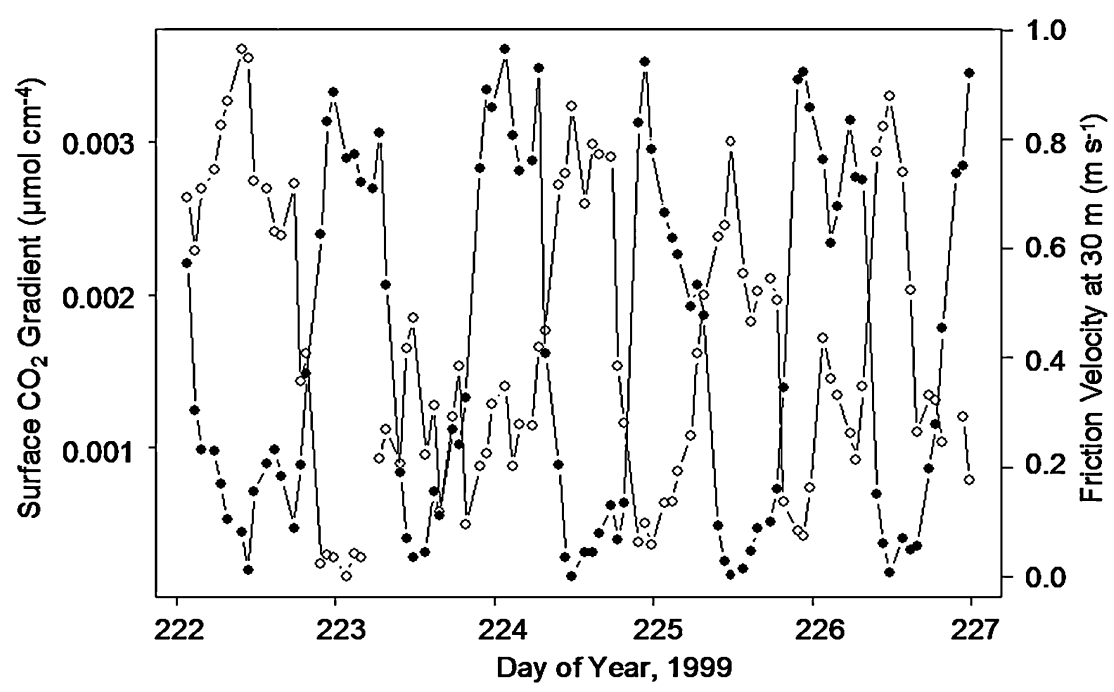




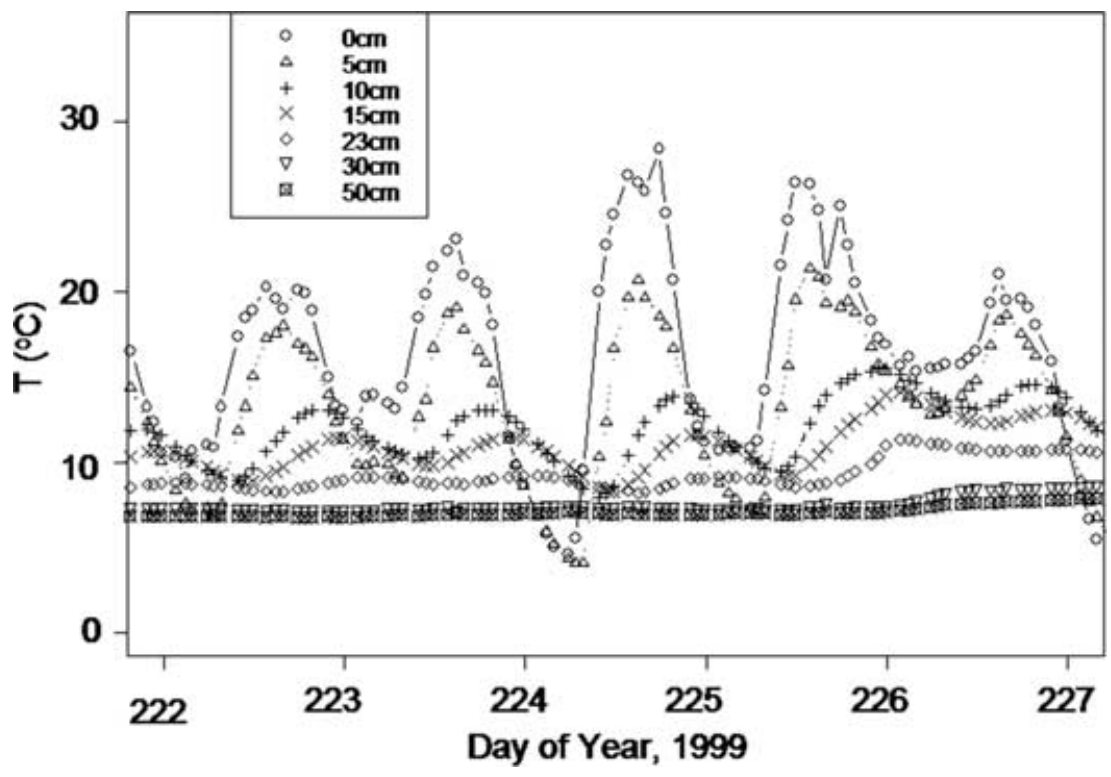

Fig 3. Temperature profile below Sphagnum moss. proportional to the flux of $\mathrm{CO}_{2}$, so higher respiration should cause a steeper gradient if diffusion dominates gas transport and effective diffusivity is constant. Respiration should be higher during the day, since the moss temperature is higher in the day (Fig. 3) and higher moss temperature is associated with higher respiration (Fig. 4). Therefore, it is likely that changes in transport near the moss surface are producing the daily cycle of the surface $\mathrm{CO}_{2}$ gradient. We hypothesize that wind flushing in the top $5 \mathrm{~cm}$ of moss is mainly responsible for this daily cycle. Friction velocity, calculated as the square root of the absolute value of the momentum flux, is a measure of atmospheric turbulence and the transfer of momentum from the atmosphere to the forest (Fig. 2). Daytime hours generally have more turbulent mixing than nighttime hours, due to the contribution of both mechanical turbulence and thermal instability caused by surface heating. Although we do not expect the friction velocity measured at $30 \mathrm{~m}$ above the forest floor to be an accurate measure of turbulent transfer at the forest floor, we find a strong negative correlation

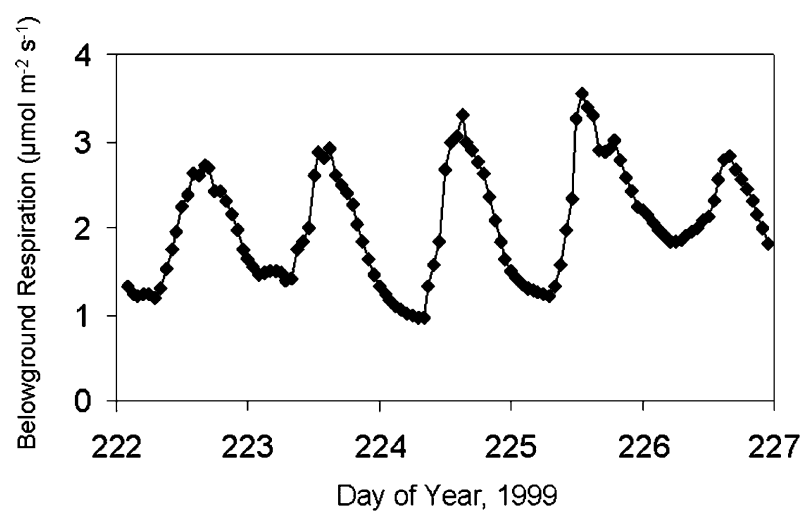

Fig 4. Total below-ground respiration calculated using eq. (3). between friction velocity at $30 \mathrm{~m}$ and the surface $\mathrm{CO}_{2}$ gradient between the atmosphere and $5 \mathrm{~cm}$ below the moss surface $\left(R^{2}=0.5\right)$ during this time period, suggesting that wind flushing is largely responsible for decreasing the surface $\mathrm{CO}_{2}$ gradient during the day. We calculate the gradient as the difference in $\mathrm{CO}_{2}$ concentration between the surface and $5 \mathrm{~cm}$ depth, divided by 5 $\mathrm{cm}$, thereby making the assumption that the gradient is linear at the surface. We note that the surface gradient increases during the evening of day 223 even though the friction velocity remains fairly high. This behaviour may be due to a small amount of rain that fell during the day $(\sim 1 \mathrm{~mm})$ that may have isolated the litter layer from the influence of the wind. Alternatively, there may be a threshold of the friction velocity required to flush the surface soil. In this case, it appears that large changes in the $\mathrm{CO}_{2}$ gradient occur when the friction velocity at $30 \mathrm{~m}$ crosses $\sim 0.4 \mathrm{~m} \mathrm{~s}^{-1}$. During the day, this threshold is crossed when wind speed at 30 $\mathrm{m}$ exceeds $2 \mathrm{~m} \mathrm{~s}^{-1}$. At night, wind above the canopy can be laminar at low wind speed, so that wind speed must exceed about 4 $\mathrm{m} \mathrm{s}^{-1}$ for friction velocity to exceed $0.4 \mathrm{~m} \mathrm{~s}^{-1}$. In the future, both friction velocity and wind speed should be measured in the understorey for two reasons. First, it is the momentum transfer near the surface (rather than the top of the canopy) that affects trace gas surface fluxes. Second, it could be determined to what degree variations in friction velocity are caused by wind versus surface heating.

If $\mathrm{CO}_{2}$ transport across the moss surface were diffusive, we would expect the $\mathrm{CO}_{2}$ flux measured by an opaque chamber to obey eq. (1). We calculated a time series of $D_{\text {eff }}$ by dividing the opaque chamber flux predicted from the moss temperature at $5 \mathrm{~cm}$, using eq. (3), by our measured $\mathrm{CO}_{2}$ gradient at the moss surface. If the flux were diffusive, we would expect $D_{\text {eff }}$ never to exceed $0.14 \mathrm{~cm}^{2} \mathrm{~s}^{-1}$ (the value in free air), and to be relatively constant, perhaps changing with soil wetting and drying. Using 
Fig 5. Effective diffusivity using eq. (1).

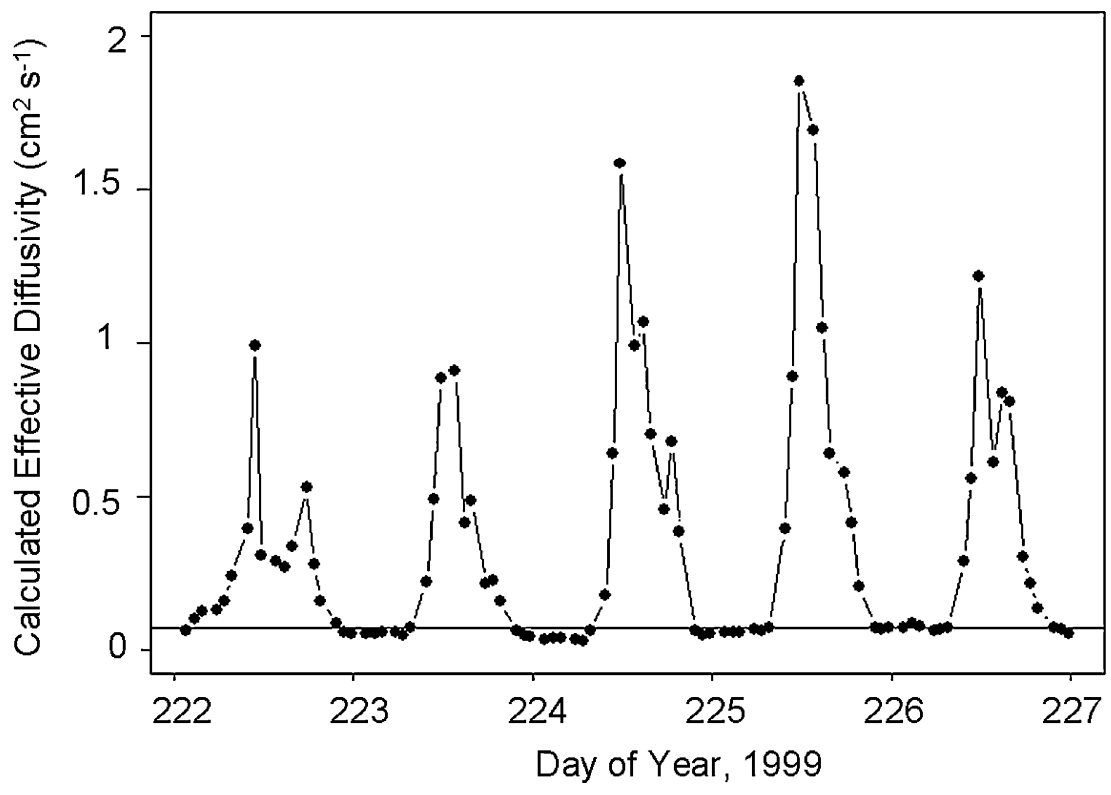

Horizontal line $=0.07 \mathrm{~cm}^{2} \mathrm{~s}^{-1}$.

eq. (3), we predict that total soil respiration varies from about 1-4 $\mu \mathrm{mol} \mathrm{m} \mathrm{m}^{-2} \mathrm{~s}^{-1}$ (Fig. 4). Rather than having a constant value, the calculated apparent effective diffusivity shows a strong daily cycle from 10-14 August (Fig. 5), with maximum values reaching $\sim 2 \mathrm{~cm}^{2} \mathrm{~s}^{-1}$. We note that our estimate of the surface flux would have to be in error by a factor of 14 , which we consider unlikely, to reduce the apparent effective diffusivity from $2 \mathrm{~cm}^{2} \mathrm{~s}^{-1}$ to 0.14 $\mathrm{cm}^{2} \mathrm{~s}^{-1}$. The minimum effective diffusivity value of $\sim 0.07 \mathrm{~cm}^{2}$ $\mathrm{s}^{-1}$ occurs at night and is the same as the value calculated for the nighttime effective diffusivity near the moss surface at this site in a previous paper (Hirsch et al., 2003) based on the physical properties of the moss and soil climate. The daily cycle in the calculated transport coefficient suggests that it is not valid to assume purely diffusive transport at the moss surface during the day at this site. The behaviour of the calculated effective diffusivity supports the idea that there is a threshold of the friction velocity that must be crossed to influence the $\mathrm{CO}_{2}$ transport below the moss surface, because of the low values calculated for the late evening and early morning despite non-zero friction velocity measured at $30 \mathrm{~m}$. Alternatively, the morning increase in turbulent momentum transfer at the surface may lag the increase at $30 \mathrm{~m}$, and the evening decrease in turbulence may occur earlier at the surface than at $30 \mathrm{~m}$. Daily changes in soil moisture at the soil surface due to condensation and evaporation could contribute to the daily cycle in apparent effective diffusivity. Unfortunately, we lack measurements of the moisture content at the moss surface. However, these moisture changes cannot explain why the apparent effective diffusivity values exceed the free air value during the day.

It is possible that the high midday values of the calculated effective diffusivity (Fig. 5) are partly due to the impact of sam- pling on the below-ground $\mathrm{CO}_{2}$ profile. If drawing air from the soil decreases the gradient between the atmosphere and $5 \mathrm{~cm}$ depth, this will increase the apparent effective diffusivity. Because the gradients are so small at midday, biases in the $5 \mathrm{~cm}$ $\mathrm{CO}_{2}$ measurements will have the biggest impact on the calculated effective diffusivity at this time. As stated in Section 2, we recorded the maximum $\mathrm{CO}_{2}$ concentration at each depth during the first minute of drawing air from the soil and also the average concentration during the second minute. The maximum concentration during the first minute might be a more accurate estimate of the "undisturbed" concentration, while the average of the second minute is generally lower. The difference between the two numbers is a measure of the degree to which drawing air from the soil affects the surface $\mathrm{CO}_{2}$ gradient. There is no sampling effect observed for the above-ground measurements, while the impact at $5 \mathrm{~cm}$ depth is always less than $25 \mathrm{ppmv}$. The overestimation of effective diffusivity caused by ignoring the effect of sampling on the $5 \mathrm{~cm}$ concentration is shown in Fig. 6 . This figure shows the ratio (surface $\mathrm{CO}_{2}$ gradient corrected for the impact of sampling)/(surface $\mathrm{CO}_{2}$ gradient not considering the impact of sampling). While the impact at night is negligible, ignoring the impact of air withdrawal on the $5 \mathrm{~cm}$ concentration during midday can lead to overestimation of the calculated effective diffusivity by a factor of 2 . Accounting for this bias still does not lower the calculated effective diffusivity below the physically reasonable maximum value of $0.14 \mathrm{~cm}^{2} \mathrm{~s}^{-1}$, however. The total respiration estimate would still have to be too high by a factor of $\sim 5$ to yield midday effective diffusivity values below 0.14 . Also, the value of the effective diffusivity on day 226 exceeds 1.0 (Fig. 5), while there is very little impact of sampling on the gradient (Fig. 6). 


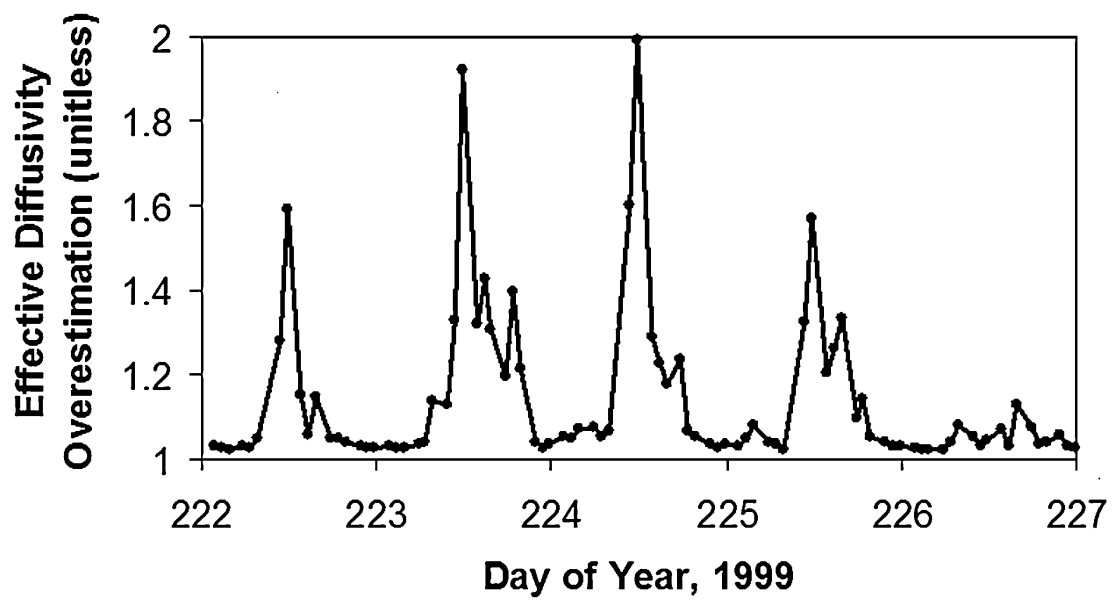

Fig 6. Overestimate of the calculated effective diffusivity in Fig. 4 due to neglecting the impact of air withdrawal on the $5 \mathrm{~cm} \mathrm{CO}_{2}$ concentration. A value of 1 signifies no bias.

\section{2. $\mathrm{CO}_{2}$ storage flux}

The soil $\mathrm{CO}_{2}$ profile shows the same temporal pattern as the surface gradient, with the entire profile decreasing in concentration during the day and increasing at night (Fig. 7). The $\mathrm{CO}_{2}$ storage corresponding to the concentration profile varies from roughly $2500-6000 \mu \mathrm{mol} \mathrm{m}^{-2}$, with high values at night and low values during the day. The first derivative of the soil $\mathrm{CO}_{2}$ storage with respect to time yields the soil pore-space $\mathrm{CO}_{2}$ storage flux, which at times reaches extremes of $\pm 0.4 \mu \mathrm{mol} \mathrm{m}^{-2}$ $\mathrm{s}^{-1}$ (Fig. 8). Positive storage flux values correspond to accumulation of $\mathrm{CO}_{2}$ in the moss litter. Some of the daytime decrease in the pore-space $\mathrm{CO}_{2}$ storage is related to the daily cycle of the above-ground $\mathrm{CO}_{2}$ concentration (see Fig. 7), since the porespace $\mathrm{CO}_{2}$ profile is connected to the atmosphere by a diffusion gradient. However, the decrease in the $\mathrm{CO}_{2}$ gradient between the surface moss litter and the atmosphere during the day suggests that wind flushing plays a role in decreasing the concentration near the top of the moss litter, and is therefore also responsible for the changes in below-ground pore-space $\mathrm{CO}_{2}$ storage. Extreme values of the hourly averaged below-canopy storage flux reach $\pm 20 \mu \mathrm{mol} \mathrm{m}^{-2} \mathrm{~s}^{-1}$ during this period, reflecting the nighttime accumulation of ecosystem respiration below the forest canopy, and the flushing and assimilation of the stored $\mathrm{CO}_{2}$ in the morning (Fig. 8).

We considered the impact of removing air from the soil during sampling on the below-ground pore-space storage flux by calculating the storage flux using the maximum $\mathrm{CO}_{2}$ observed at each depth during the first minute of sampling at that depth, as opposed to the average concentration during the second minute. The effect on the below-ground pore-space storage flux is always less than $0.1 \mu \mathrm{mol} \mathrm{m}^{-2} \mathrm{~s}^{-1}$, which can be large relative to the porespace storage flux but is quite small compared with the difference between the pore-space storage flux and the above-ground storage flux. Therefore, in general we conclude that the pore-space $\mathrm{CO}_{2}$ storage flux in the top $20 \mathrm{~cm}$ is negligible compared with

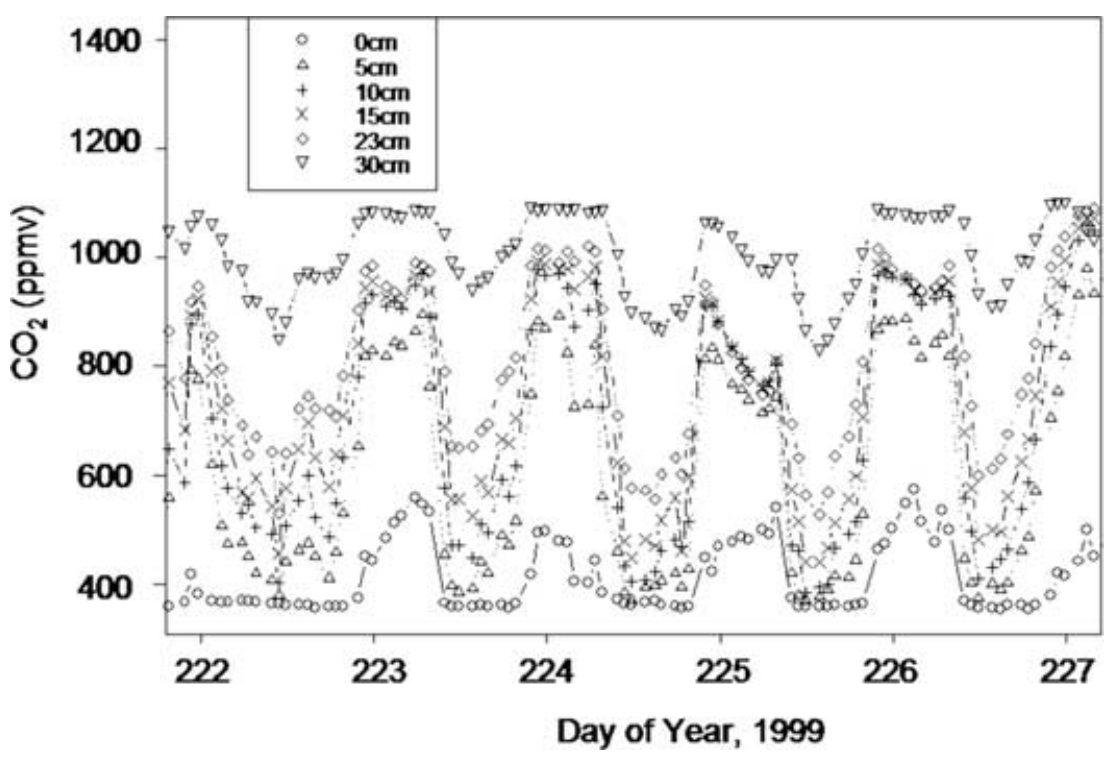

Fig 7. $\mathrm{CO}_{2}$ profile below Sphagnum moss. 
Fig 8. Below-ground pore-space $\mathrm{CO}_{2}$ storage flux (data points and 3-h running average, black curve) and below-canopy $\mathrm{CO}_{2}$ storage flux (3-h running average, grey curve).

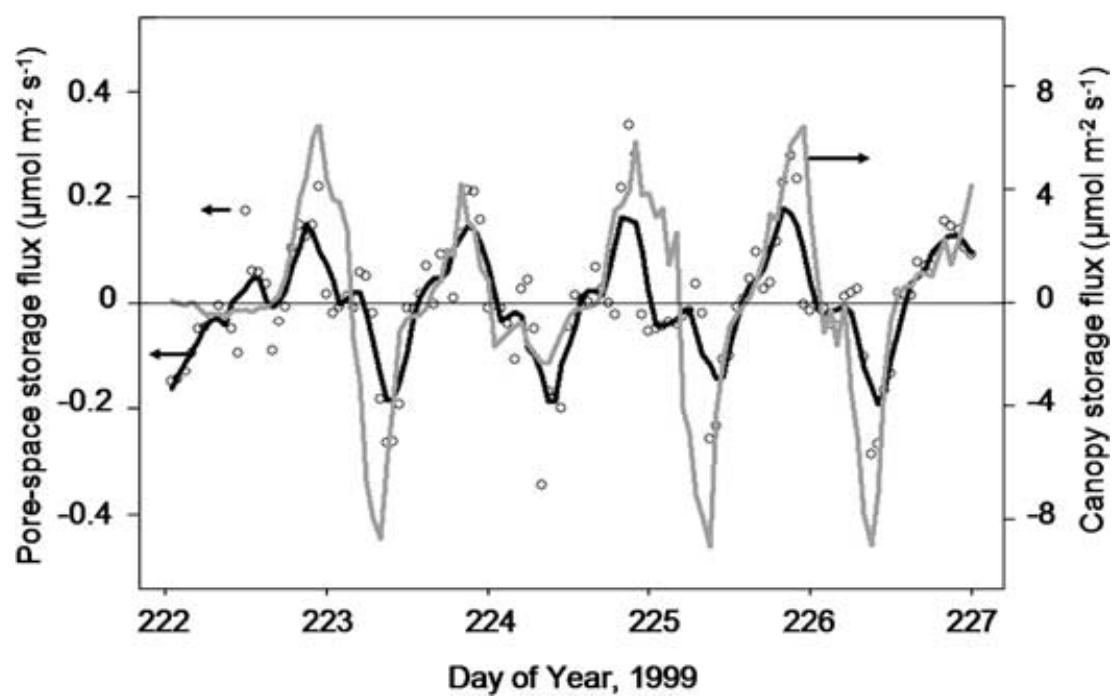

the above-ground storage flux. We find that the pore-space $\mathrm{CO}_{2}$ storage flux occasionally exceeds $5 \%$ of the canopy storage flux during the morning or afternoon when the soil pore-space $\mathrm{CO}_{2}$ storage is changing most rapidly. The below-ground pore-space storage flux could be a larger fraction of the soil respiration flux, which we predict is in the range of $1-4 \mu \mathrm{mol} \mathrm{m}^{-2} \mathrm{~s}^{-1}$; however, the surface flux must be measured directly over the profile measurements, at the same time, to gain a sense of how the two are related.

\subsection{The possible influence of moss photosynthesis}

Another process that could decrease the surface $\mathrm{CO}_{2}$ gradient (and also pore-space $\mathrm{CO}_{2}$ storage) at the surface, and therefore boost apparent effective diffusivity, is consumption of pore-space $\mathrm{CO}_{2}$ by moss net photosynthesis (Brooks et al., 1997). Isotopic evidence collected during the BOREAS Project suggests that only a small proportion of moss photosynthate is derived from pore-space $\mathrm{CO}_{2}$ near the moss surface. Moss isotopic discrimination during photosynthesis at the BOREAS Northern Study Area is approximately 23.5 per mille (Brooks et al., 1997). The isotopic signature of living Sphagnum and feather mosses in the BOREAS Northern Study Area is about -31 to -33 per mille. Therefore, the source $\mathrm{CO}_{2}$ for moss photosynthesis is close to the free atmospheric value of -8 per mille. A more depleted isotopic value would be expected if the moss were mostly consuming $\mathrm{CO}_{2}$ from the soil profile rather than from the atmosphere. For comparison, the daily average $\delta^{13} \mathrm{C}$ signature of $\mathrm{CO}_{2}$ collected by the automated system at $5 \mathrm{~cm}$ below the Sphagnum surface was -15 to -17 per mille (Hirsch, 2001). If a substantial proportion of moss photosynthate came from $\mathrm{CO}_{2}$ at this depth, the moss $\delta^{13} \mathrm{C}$ signature would be lower than is observed. Also, the concentration at $5 \mathrm{~cm}$ below the moss surface never decreases below the atmospheric concentration, which might be expected to happen if photosynthesis were exerting a strong influence on the $\mathrm{CO}_{2}$ concentration below the surface. We do not rule out the influence of moss photosynthesis as a control on the surface $\mathrm{CO}_{2}$ gradient; however, testing this hypothesis requires reliable measurements of insolation and net $\mathrm{CO}_{2}$ exchange at the moss surface, which were not available for this study.

\subsection{The impact of sampling on the below-ground $\mathrm{CO}_{2}$ profile}

We have seen that removing air from the soil during sampling has a large impact on the measured $\mathrm{CO}_{2}$ gradient near the moss surface and on the pore-space storage flux. We must also consider whether the $\mathrm{CO}_{2}$ gradient in the soil has time to recover to its "undisturbed" value between hourly sampling periods. Each point in the profile is sampled for $2 \mathrm{~min}$ at a rate of $120 \mathrm{sccm}$, for a total of $240 \mathrm{sccm}$ withdrawn each hour. The air-filled porosity is $80 \%$ at $5 \mathrm{~cm}$ and $60 \%$ at $20 \mathrm{~cm}$ while total porosity is $0.98 \mathrm{~cm}^{3}$ $\mathrm{cm}^{-3}$ at $5 \mathrm{~cm}$ and $0.95 \mathrm{~cm}^{3} \mathrm{~cm}^{-3}$ at $20 \mathrm{~cm}$ depth (Hirsch et al., 2003). The volume affected by this sampling can be modelled as either a cylinder, assuming even sampling along the $25 \mathrm{~cm}$ long microporous Teflon tube, or as a sphere, assuming sampling from the very end of the tube closest to the sampling system. If the volume affected is treated as a cylinder, a cylinder of radius $\sim 2 \mathrm{~cm}$ is removed at either depth. If treated as a sphere, the affected radius is closer to $4 \mathrm{~cm}$. The time scale for a diffusive process to approach a steady state, assuming a uniform diffusivity, is given by the following relationship (Crank, 1975, page 51):

$L=l^{2} / 6 D$.

Here, $L$ is the time scale, $l$ is distance and $D$ is effective diffusivity. The steady state is reached when $D t / l^{2}$ is approximately 0.45 (about three times $L$ ). For all cases considered, the maximum time to return to steady state is about $4 \mathrm{~min}$, assuming that the disturbance at each depth is treated as a sphere, air-filled porosity is $60 \%$, total porosity is $0.95 \mathrm{~cm}^{3} \mathrm{~cm}^{-3}$ and effective diffusivity 
is $0.03 \mathrm{~cm}^{2} \mathrm{~s}^{-1}$ (Hirsch et al., 2003) at $20 \mathrm{~cm}$ depth. It seems reasonable, then, that the profile could recover on the time scale of an hour, even at $20 \mathrm{~cm}$ depth, due to the small disturbed volume and high diffusivity accompanying high air-filled porosity in the moss litter. Of course, this situation would be different under waterlogged conditions or in a mineral soil with lower porosity.

\section{Summary and conclusions}

Using high-temporal-resolution measurements with an automated soil $\mathrm{CO}_{2}$ profile sampling system we have shown that both the soil surface $\mathrm{CO}_{2}$ gradient and pore-space $\mathrm{CO}_{2}$ storage are very dynamic in a highly porous boreal litter layer. Therefore, assuming diffusive transport at the moss surface or unchanging pore-space $\mathrm{CO}_{2}$ storage during the day, or under turbulent conditions in general, is not justified at the site and may not be justified at other sites with highly porous litter layers. We find that the magnitude of the pore-space $\mathrm{CO}_{2}$ storage flux that accompanies the daily cycles in the above-ground $\mathrm{CO}_{2}$ concentration and surface transport is small relative to the below-canopy storage flux. Because the surface $\mathrm{CO}_{2}$ flux measured by flux chambers is only a fraction of the net ecosystem exchange, the change in the litter pore-space $\mathrm{CO}_{2}$ storage could be significant compared with flux chamber measurements. Measurements of the below-ground pore-space storage flux would be a valuable addition to future hand-held and automated flux chamber studies. If the pore-space storage flux were found to be significant relative to the surface flux, it could be used to correct the surface flux in a manner analogous to the correction of eddy covariance flux measurements using the below-canopy storage flux.

Hand-sampled, hourly measurements of the below-ground $\mathrm{CO}_{2}$ profile over the course of several days can be used to diagnose the magnitude of the pore-space $\mathrm{CO}_{2}$ storage flux and to determine the dynamics of the surface concentration gradient. Future studies of the behaviour of $\mathrm{CO}_{2}$ concentrations in the litter layer should also include careful measurements of the momentum flux at the forest floor and measurements of photosynthetic activity by low-stature plants (e.g. bryophytes) on the forest floor in order to assess their impact on both changes in $\mathrm{CO}_{2}$ storage and on the surface $\mathrm{CO}_{2}$ gradient. Accurate measurements of soil moisture should be included to allow calculation of soil $\mathrm{CO}_{2}$ storage changes and effective diffusivity changes that accompany soil wetting and drying, both due to rainfall and daily condensation and evaporation. It is possible that some of the daily changes in near-surface transport are related to changes in near-surface soil moisture due to condensation and evaporation. Lastly, future studies of this type should include detailed in situ experiments to quantify the impact of removal of soil air on the $\mathrm{CO}_{2}$ profile, and the recovery from that disturbance. Methods that allow sampling of below-ground $\mathrm{CO}_{2}$ concentrations without disturbance of the $\mathrm{CO}_{2}$ profile, while more difficult to calibrate, show promise in alleviating this source of uncertainty (Hirano et al., 2003).

\section{Acknowledgments}

The authors would like to thank Abigail Hirsch and Gloria Rapalee for assistance in the field and David Risk, Hugo Beltrami and an anonymous reviewer for their insightful comments on the manuscript. The work presented in this paper was supported by grants from the US National Aeronautics and Space Administration (NAG5-7534 to Harvard University), the US National Science Foundation (616F965 to UC Irvine), the US Department of Energy (DE-F603-00ER63026 to UC Irvine), the A. W. Mellon Foundation (to S. Trumbore) and by a NASA Earth System Science Fellowship (A. Hirsch).

\section{References}

Brooks, J .R., Flanagan, L. B., Buchmann, N. and Ehleringer, J. R. 1997. Carbon isotope composition of boreal plants: functional grouping of life forms. Oecologia 110, 301-311.

Clements, W. E. and Wilkening, M. H. 1974. Atmospheric Pressure Effects on ${ }^{222} \mathrm{Rn}$ Transport Across the Earth-Air Interface. J. Geophys. Res. 79(33), 5025-5029.

Crank, J. 1975. The Mathematics of Diffusion, 2nd Edition. Oxford University Press, London.

Davidson, E. A. and Trumbore, S. E. 1995. Gas diffusivity and production of $\mathrm{CO}_{2}$ in deep soils of the eastern Amazon. Tellus 47B, 550565 .

Gaudinski, J. B., Trumbore, S. E., Davidson, E. A. and Zheng, S. 2000. Soil carbon cycling in a temperate forest: radiocarbon-based estimates of residence times, sequestration rates and partitioning of fluxes. Biogeochemistry 51, 33-69.

Goulden, M. L. and Crill, P. M. 1997. Automated measurements of $\mathrm{CO}_{2}$ exchange at the moss surface of a black spruce forest. Tree Physiol. 17, 537-542.

Goulden, M. L., Daube, B. C., Fan, S.-M., Sutton, D. J., Bazzaz, A. et al. 1997. Physiological responses of a black spruce forest to weather. J. Geophys. Res. 102(D24), 28 987-29008.

Goulden, M. L., Wofsy, S. C., Harden, J. W., Trumbore, S. E., Crill, P. M. et al. 1998. Sensitivity of boreal forest carbon balance to soil thaw. Science 279, 214-217.

Hirano, T., Kim, H. and Tanaka, Y. 2003. Long-term half-hourly measurement of soil $\mathrm{CO}_{2}$ concentration and soil respiration in a temperate deciduous forest. J. Geophys. Res. 108(D20), 4631, doi:10.1029/2003JD003766.

Hirsch, A. I. 2001. Physical and biological controls on the soil $\mathrm{CO}_{2}$ profile. Ph.D. Dissertation, Department of Earth System Science, University of California, Irvine.

Hirsch, A. I., Trumbore, S. E. and Goulden, M. L. 2003. Direct measurement of the deep soil respiration accompanying seasonal thawing of a boreal forest soil. J. Geophys. Res. 107(D3), 8221, doi:10.1029/2001JD000921.

Kimball, B. A. and Lemon, E. R. 1971. Air turbulence effects upon soil gas exchange. Proc. Soil Sci. Soc. Am. 35, 16-21.

Lund, C. P., Riley, W. J., Pierce, L. L. and Field, C. B. 1999. The effects of chamber pressurization on soil-surface $\mathrm{CO}_{2}$ flux and the implications for NEE measurements under elevated $\mathrm{CO}_{2}$. Global Change Biol. 5 , 269-281. 
Newcomer, J., Landis, D., Conrad, S., Curd, S., Huemmrich, K. et al. 2000. Collected Data of the Boreal Ecosystem-Atmosphere Study. CD-ROM. NASA Goddard Space Flight Center, Greenbelt, Maryland, USA.

Renault, P., Mohrath, D., Gaudu, J.-C. and Fumanal, J.-C. 1998. Air pressure fluctuations in a prairie soil. Soil Sci. Soc. Am. J. 62, 553563.

Risk, D., Kellman, L. and Beltrami, H. 2002a. Carbon dioxide in soil profiles: production and temperature dependence. Geophys. Res. Lett. 29, doi:10.1029/2001GL014002.

Risk, D., Kellman, L. and Beltrami, H. 2002b. Soil $\mathrm{CO}_{2}$ production and surface flux at four climate observatories in eastern Canada. Global Biogeochem. Cycles 16(4), 1122, doi:10.1029/2001GB001831.

Schery, S. D., Gaeddert, D. H. and Wilkening, M. H. 1984. Factors affecting exhalation of radon from a gravelly sandy loam. J. Geophys. Res. 89(D5), 7299-7309.

Sellers, P. J., Hall, F. G., Kelly, R. D., Black, A., Baldocchi, D. et al. 1997. BOREAS in 1997: experiment overview, scientific results, and future directions. J. Geophys. Res. 102(D24), 28 731-28 770.

Trumbore, S. E. and Harden, J. W. 1997. Accumulation and turnover of carbon in organic and mineral soils of the BOREAS northern study area. J. Geophys. Res. 102(D24), 28 817-28 830. 